\title{
Exposure-response analysis and risk assessment for silica and silicosis mortality in a pooled analysis of six cohorts
}

\author{
A 't Mannetje, K Steenland, M Attfield, P Boffetta, H Checkoway, N DeKlerk, \\ R-S Koskela
}

Occup Environ Med 2002;59:723-728

See end of article for authors' affiliations ......................

Correspondence to: Ms A 't Mannetje, International Agency for Research on Cancer, Unit of Environmental Cancer Epidemiology, 150 Cours Albert Thomas, 69372 Lyon Cedex 08, France; mannetje@iarc.fr

Accepted 10 April 2002

\begin{abstract}
Aims: To study the relation between exposure to crystalline silica and silicosis mortality. Although mortality is an important endpoint for regulators, there have been no exposure-response studies for silicosis mortality, because of the relative rareness of silicosis as an underlying cause of death, and the limited availability of quantitative exposure estimates.

Methods: Data from six occupational cohorts were pooled with good retrospective exposure data in which 170 deaths from silicosis were reported. Standard life table analyses, nested case-control analyses, and risk assessment were performed.

Results: The rate of silicosis mortality in the combined data was $28 / 100000$ py, increasing in nearly monotonic fashion from $4.7 / 100000$ for exposure of $0-0.99 \mathrm{mg} / \mathrm{m}^{3}$-years to $233 / 100000$ for exposure of $>28.1 \mathrm{mg} / \mathrm{m}^{3}$-years. The estimated risk of death up to age 65 from silicosis after 45 years of exposure at $0.1 \mathrm{mg} / \mathrm{m}^{3}$ silica (the current standard in many countries) was 13 per 1000, while the estimated risk at an exposure of $0.05 \mathrm{mg} / \mathrm{m}^{3}$ was 6 per 1000 . Both of these risks are above the risk of 1 per 1000 typically deemed acceptable by the US OSHA.

Conclusion: The findings from this pooled analysis add further support to the need to control silica exposure and to lower the occupational standards. Our estimates of lifetime silicosis mortality risk are probably underestimates as, in addition to exposure misclassification, our study might have suffered from outcome misclassification in that silicosis deaths might have been coded to other related causes, such as tuberculosis or chronic obstructive pulmonary disease.
\end{abstract}

$\mathrm{R}$ espirable exposure to crystalline silica has long been known to produce fibrotic nodules in the lungs. This crippling disease was named silicosis, after its causal agent. The disease can progress from "simple silicosis", characterised by few symptoms and little lung impairment or disability, to progressive massive fibrosis (PMF), characterised by increasing impairment in lung function and disability, often leading to respiratory failure and death. PMF typically develops over many years of exposure to crystalline silica. A less common form of silicosis is "acute silicosis", caused by inhalation of high concentrations of silica that can occur in very poorly controlled exposure conditions, and which has a high fatality rate.

Many workers are still exposed to crystalline silica in industries that involve the fragmentation or processing of silica containing rock or sand, such as mining, construction, stone and sand production, manufacture of clay and glass products, and foundries. There are an estimated 3200000 workers exposed in the European Union, ${ }^{1}$ and 1700000 in the United States. ${ }^{2}$ Many more workers are likely to be exposed in developing countries. ${ }^{3}$ The US Occupational Safety and Health Administration's (OSHA) permissible exposure limit (PEL) is $0.10 \mathrm{mg} / \mathrm{m}^{3}$ for an eight hour time weighted average exposure to respirable crystalline silica. NIOSH has recommended an exposure limit of $0.05 \mathrm{mg} / \mathrm{m}^{3}$ as a time weighted average for up to 10 hours per day during a 40 hour week.

Several studies have attempted to quantify the relation between exposure to crystalline silica and silicosis morbidity. A recent review of the literature by Greaves ${ }^{4}$ focuses on three studies $^{5-7}$ with follow up extending after employment, because silicosis frequently occurs after leaving work. Greaves concludes that the risk of silicosis (ILO category $1 / 0$ or more) following a lifetime of exposure at the exposure limit of 0.05 $\mathrm{mg} / \mathrm{m}^{3}$ is likely to be $20-40 \%$. Recent risk assessments for silicosis in tin miners ${ }^{8}$ and diatomaceous earth workers ${ }^{9}$ support Greaves' conclusions.
The exposure-response relation between exposure and silicosis mortality is seldom studied because of the relatively small numbers of deaths for which silicosis is reported as underlying cause on the death certificate. Some studies, for example Checkoway and colleagues, ${ }^{10}$ have considered exposure-response for the broader category of non-malignant respiratory disease mortality. Silicosis mortality, besides silicosis morbidity, is nonetheless an important endpoint for the purposes of regulation and risk assessment, which can complement findings on the relation between silica and silicosis morbidity. Another reason for looking at mortality besides morbidity is the often expressed concern that silicosis morbidity can be defined in different ways, and can include non-symptomatic silicosis only detectable through chest $x$ rays as well as clinical disease. Differential definitions of silicosis morbidity can cause heterogeneity between studies, while this is less the case for mortality.

\section{MATERIALS AND METHODS \\ Selection of the cohorts}

We reviewed the literature to identify all occupational cohorts for which quantitative exposure assessment was available or for which quantitative exposure data could be developed. Thirteen cohorts were identified, of which 10 were included in a pooled analysis for lung cancer. ${ }^{11}$ For the analysis for silicosis presented here, we retained six cohorts, which are briefly described in the following paragraphs and table 1.

Abbreviations: ICD, International Classification of Disease; JEM, job-exposure matrix; OSHA, Occupational Safety and Health Administration; PEL, permissible exposure limit; PMF, progressive massive fibrosis 
Table 1 Description of the six studies

\begin{tabular}{|c|c|c|c|c|c|c|c|c|}
\hline \multirow[b]{2}{*}{ Study } & \multirow[b]{2}{*}{ Reference } & \multirow[b]{2}{*}{$\begin{array}{l}\text { Number } \\
\text { of workers }\end{array}$} & \multirow[b]{2}{*}{$\begin{array}{l}\text { End of } \\
\text { follow } \\
\text { up }\end{array}$} & \multirow[b]{2}{*}{$\begin{array}{l}\text { Number of } \\
\text { deaths }\end{array}$} & \multirow[b]{2}{*}{$\begin{array}{l}\text { Number of } \\
\text { silicosis } \\
\text { deaths } †\end{array}$} & \multicolumn{3}{|c|}{$\begin{array}{l}\text { Estimated exposure to respirable } \\
\text { crystalline silica in the cohort }\end{array}$} \\
\hline & & & & & & $\begin{array}{l}\text { Median } \\
\text { duration (y) }\end{array}$ & $\begin{array}{l}\text { Median } \\
\text { average } \\
\left(\mathrm{mg} / \mathrm{m}^{3}\right)\end{array}$ & $\begin{array}{l}\text { Median } \\
\text { cumulative } \\
\left(\mathrm{mg} / \mathrm{m}^{3}-\mathrm{y}\right)\end{array}$ \\
\hline 1. US diatomaceous earth workers & Checkoway et al (1997) & 2342 & 1994 & 749 & 15 & 4.3 & 0.18 & 1.05 \\
\hline 2. Finnish granite workers & Koskela et al (1994) & 1026 & $1993 *$ & 418 & 14 & 9.2 & 0.59 & 4.63 \\
\hline 3. US granite workers & Costello et al (1988) & 5408 & 1982 & 1762 & 43 & 18.0 & 0.05 & 0.71 \\
\hline 4. US industrial sand workers & Steenland et al (2001) & 4027 & 1996 & 860 & 15 & 3.7 & 0.04 & 0.13 \\
\hline 5. US gold miners & Steenland et al (1995) & 3348 & $1996 *$ & 1925 & 39 & 5.4 & 0.05 & 0.23 \\
\hline 6. Australian gold miners & De Klerk et al (1998) & 2213 & 1993 & 1351 & 44 & 26.8 & 0.43 & 11.37 \\
\hline Total & & 18364 & & 7065 & 170 & 10.4 & 0.07 & 0.62 \\
\hline
\end{tabular}

(1) US diatomaceous earth workers. This is a historical cohort mortality study of 2342 male workers exposed to crystalline silica (predominantly cristobalite) in a diatomaceous earth mining and processing facility in California. ${ }^{10}$ Estimated exposure levels have been described by Seixas and colleagues, ${ }^{12}$ and were available for each worker from the original data.

(2) Finnish granite workers. This cohort consisted of 1026 workers hired between 1940 and 1971, in granite quarries and processing sites in three main granite areas of Finland. ${ }^{13-16}$

Koskela and colleagues ${ }^{15}$ have previously developed exposure estimates for subjects in nested case-control analyses of this cohort. For the purpose of this pooled analysis, the authors have applied the approach used in the case-control study to all members in the cohort. In addition they extended the mortality follow up from 1989 to 1993.

(3) US (Vermont) granite workers. This cohort consisted of 5408 workers from the Vermont granite industry including quarries, where the stone is cut, and sheds, where the stone is processed..$^{18}$ Follow up for the pooled analysis was not extended beyond the original date of 1982, although some additional deaths prior to that were identified and added to the data. Attfield and Costello ${ }^{19}$ developed job and time specific quantitative exposures estimates for this cohort, using published data on the exposure to silica of the Vermont granite workers previously summarised by Davis and colleagues ${ }^{17}$ from six industrial hygiene surveys undertaken between 1924 and 1977. ${ }^{20-25}$

(4) US industrial sand workers. This cohort consists of 4027 workers in the industrial sand industry in the United States. Work in this industry consists of aboveground quarrying of ore with a high silica content, which is then ground and crushed, often into very pure and fine silica called silica flour. ${ }^{25 a}$ The authors developed quantitative job and time specific estimates of exposure based on extensive data from the 1970s and 1980s collected at all 18 plants in the study, as well as more limited data collected at a number of industrial sand plants in the 1940s. ${ }^{26}$

(5) US gold miners. This is a cohort of 3348 underground gold miners exposed to silica in South Dakota. ${ }^{67}$ For the pooled analysis, follow up was updated from 1990 to 1996. Quantitative job and time specific estimates of exposure $\left(\mathrm{mg} / \mathrm{m}^{3}\right.$ respirable silica) were available for this cohort, ${ }^{28}{ }^{29}$ as were detailed work histories.

(6) Australian gold miners. This cohort consisted of 2213 underground gold miners in Kalgoorlie, Western Australia and was established from surveys of respiratory function and symptoms in underground gold miners. $^{30}{ }^{31}$ For this pooled analysis, the authors developed job and time specific exposure estimates $\left(\mathrm{mg} / \mathrm{m}^{3}\right.$ respirable silica). These estimates were based on industrial hygiene data collected since 1925 in the Australian gold mines. ${ }^{32}$

Four other cohorts, one from South Africa ${ }^{5}$ and three from China, ${ }^{33}$ for which quantitative exposure estimates of silica were available, were included in the pooled analysis for lung cancer. ${ }^{11}$ However, they were not included in this analysis because of a differential definition for silicosis in coding of causes of death: the three Chinese studies did not use the International Classification of Disease (ICD) system to code death certificates, and there is uncertainty regarding how to apply the original categories for silicosis, pneumoconiosis, and silicotuberculosis in the pooled analysis. Furthermore, the principal investigators of the Chinese cohorts are preparing their own report on silicosis and therefore preferred not to include their data on silicosis mortality in this pooled analysis. In the case of the South African study, ${ }^{35}$ there were no deaths coded with silicosis as underlying cause, despite the documentation of high rates of silicosis in this cohort. ${ }^{5}$ Discussions with the principal investigator (personal communication, Eva Hnizdo) suggested that in South Africa silicosis was not generally considered an underlying cause of death. It is of note that we found in this cohort strong exposure-response related trends in mortality from related causes of death-that is, tuberculosis and non-specific chronic obstructive pulmonary disease.

In total, the pooled data set included 170 deaths with silicosis and unspecified pneumoconiosis as underlying cause, originating from a working population of 18364 individuals. Table 1 lists the relevant studies with references and descriptive data.

\section{Exposure data}

The original data were obtained from each investigator. All exposure estimates were either originally in terms of milligrams of respirable silica per cubic metre of air, or were converted to this unit. We have reported details on the exposure data as well as the process of creating a common exposure metric. ${ }^{36}$ Job-exposure matrices (JEMs) for all six cohorts permitted exposure estimation of plant specific, job specific, and calendar-time specific exposure levels. The JEMs were typically based on a large number of actual measurements, supplemented by opinions from experts with extensive knowledge of the industries concerned.

\section{Analyses}

For all six cohorts, silicosis deaths were defined for the pooled analysis as those with underlying cause of death silicosis (ICD9 502) or unspecified pneumoconiosis (ICD9 505). This definition of outcome was conservative; it is likely that some 
Table 2 Exposure specific mortality rates and mortality rate ratios from silicosis

\begin{tabular}{|c|c|c|c|c|c|}
\hline \multirow{2}{*}{$\begin{array}{l}\text { Cumulative exposure to } \\
\text { crystalline silica } \\
\left(\mathrm{mg} / \mathrm{m}^{3}-\mathrm{y}\right)\end{array}$} & \multirow{2}{*}{$\begin{array}{l}\text { Person years } \\
(\times 100000)\end{array}$} & \multirow{2}{*}{$\begin{array}{l}\text { Silicosis mortality rate } \\
\text { (per } 100000 \text { py)* }\end{array}$} & \multirow{2}{*}{$\begin{array}{l}\text { Adjustedt silicosis mor- } \\
\text { tality rate (per } 100000 \\
\text { py) }\end{array}$} & \multicolumn{2}{|c|}{ Adjusted $†$ rate ratio } \\
\hline & & & & $R R$ & $(95 \% \mathrm{Cl})$ \\
\hline $0-0.99$ & 3.637 & 4.7 & 4.7 & 1.00 & (referent) \\
\hline $0.99-1.97$ & 0.631 & 26.9 & 15.9 & 3.39 & (1.42 to 8.08$)$ \\
\hline $1.97-2.87$ & 0.291 & 58.4 & 29.2 & 6.22 & $(2.56$ to 15.12$)$ \\
\hline $2.87-4.33$ & 0.252 & 67.4 & 44.2 & 9.40 & (3.71 to 23.80 ) \\
\hline $4.33-7.12$ & 0.278 & 61.1 & 64.3 & 13.69 & (5.04 to 37.18 ) \\
\hline $7.12-9.58$ & 0.188 & 90.6 & 106.4 & 22.64 & $(7.88$ to 65.10$)$ \\
\hline $9.58-13.21$ & 0.204 & 83.2 & 112.6 & 23.97 & (8.05 to 71.32 ) \\
\hline $13.21-15.89$ & 0.118 & 144.7 & 189.2 & 40.25 & (13.25 to 122.3 ) \\
\hline $15.89-28.10$ & 0.231 & 73.6 & 118.0 & 25.11 & (8.09 to 77.91 ) \\
\hline$>28.10$ & 0.073 & 233.6 & 299.1 & 63.63 & (19.87 to 203.8 ) \\
\hline Total & 5.903 & 28.8 & n.a. & n.a. & n.a. \\
\hline
\end{tabular}

*Each category includes 17 silicosis deaths (total 170).

†Adjusted for age in four categories, calendar period in eight categories, study in six categories, using Poisson regression.

n.a., not applicable.

silicosis was coded to other causes such as tuberculosis or chronic obstructive pulmonary disease with no mention of pneumoconiosis. Of the 170 silicosis deaths in our analysis, 150 were from silicosis and 20 were from unspecified pneumoconiosis.

We conducted standard life table analyses of silicosis mortality of the combined data, using 10 categories of cumulative exposure. ${ }^{6}$ The cut points for the 10 categories were chosen by dividing the cumulative exposure of the 170 silicosis deceased into deciles. Poisson regression was used to calculate rate ratios using the lowest exposure category as referent, including age, calendar period, and study in the model as potential confounders.

More detailed analyses of the exposure-response were conducted via a nested case-control analysis. The cases were defined again as those with underlying cause of death silicosis (ICD9 502) or unspecified pneumoconiosis (ICD9 505). For each case $(n=170)$, a risk set was assembled composed of those who had survived to an age at least as great as the case, and which was matched for race (relevant only for US studies), sex, date of birth (within five years), and study to the index case. One hundred controls were randomly drawn from each risk set to be compared to the index case, sufficient to assure good statistical precision and a point estimate very close to the point estimate that would have been obtained using full risk sets. ${ }^{37}$

The pooled case-control analysis was conducted using conditional logistic regression (in which the likelihood is equivalent to Cox regression), using the PHREG procedure of SAS. ${ }^{38}$ This analysis permitted flexible modeling of different exposure metrics and lags, and avoided the inherent categorisation of Poisson regression. We considered cumulative exposure ( $\mathrm{mg} / \mathrm{m}^{3}$-years), average exposure over working period $(\mathrm{mg} /$ $\left.\mathrm{m}^{3}\right)$, peak exposure over working period $\left(\mathrm{mg} / \mathrm{m}^{3}\right)$, and duration of exposure (years), and logarithmic transformations of these variables. We also considered lags of 0, 5, 10, 15, and 20 years. A priori there was no reason to believe that a lag was necessary, in that at least some types of silicosis can develop rapidly after exposure. However, we nonetheless investigated whether the data could be modelled better using a lag, since we knew that in many cases silicosis develops years after exposure ceases. Constants of 1.0 and 0.005 were added to cumulative exposure or average exposure respectively, when taking the logarithms, to avoid taking the logarithm of 0 in lagged analyses. We also ran some analyses using a cubic spline model with five knots $(5 \%, 25 \%, 50 \%, 75 \%, 95 \%$ of the distribution); this is a very flexible exposure-response model, free from the usual parametric restraints inherent in many of the models specified above. ${ }^{39}$

Heterogeneity of exposure effect between the studies was considered via assessment of interaction terms between study and exposure. Heterogeneity by age was considered by stratifying by age ( $<65$ years and $\geqslant 65$ years) and including an ageexposure interaction term.

Risk assessment was based on the absolute rates of silicosis by cumulative exposure (adjusted for age, calendar time, and study). Cumulative lifetime risk of death from silicosis through age 65 was calculated by standard formulas for converting rates to risks (risk $=1-\exp \left[-\sum\right.$ time*rate $]$ ), where time is divided in intervals of one year).$^{40}$ In these analyses, risk was calculated from age 20 to age 65 , and assumed to be constant after leaving work and ending exposure. For each year from age 20 to 65 , cumulative exposure increased depending on what exposure intensity was assumed (we considered 0.1 $\mathrm{mg} / \mathrm{m}^{3}$ and $0.05 \mathrm{mg} / \mathrm{m}^{3}$ ), and the rates over time increased correspondingly (for example, at an intensity of $0.1 \mathrm{mg} / \mathrm{m}^{3}$ after 10 years (age 20-29) the cumulative exposure was $1.0 \mathrm{mg} / \mathrm{m}^{3}$ years, and the rate increased in that year from 4.7/100 000 to 15.9/100 000; see table 2). The first level considered (0.1 $\mathrm{mg} / \mathrm{m}^{3}$ ) is currently used as the permissible level for crystalline silica (quartz) in a number of countries in the world; the second $\left(0.05 \mathrm{mg} / \mathrm{m}^{3}\right)$ is the NIOSH recommended exposure limit.

\section{RESULTS}

The age of death for the 170 silicosis deceased ranged between 32 and 91 years, with a mean of 68.7 (SD 9.65). Of all silicosis deaths, 9\% $(n=16)$ had occurred within one year after leaving the job. Fifteen of these 16 workers had a long duration of exposure prior to leaving the job, suggesting the development of a chronic disease rather than acute silicosis. Overall, those who died of silicosis had a median duration of exposure of 28 years and a median cumulative exposure of $7.15 \mathrm{mg} / \mathrm{m}^{3}$-years (compared to respectively 10 years and $0.62 \mathrm{mg} / \mathrm{m}^{3}$-years for the whole cohort). The median average exposure of the 170 silicosis deceased was $0.26 \mathrm{mg} / \mathrm{m}^{3}$, compared to 0.07 for the whole cohort.

\section{Life table analysis and Poisson regression}

The silicosis mortality rate was 28.8 per 100000 person years for the whole cohort (table 2). The mortality rates for each decile of cumulative exposure to crystalline silica, increased from 4.7 per 100000 person years for the lowest exposure category (less than $1 \mathrm{mg} / \mathrm{m}^{3}$-years), to 233 per 100000 person years in the highest exposure category (more than $28 \mathrm{mg} / \mathrm{m}^{3}$ years). When adjusted for age, calendar period, and study, a rate ratio of 64 (95\% CI 19.87 to 203.8) was found for the highest exposure category compared to the lowest. The increase of rate ratio by increasing cumulative exposure was almost monotonic. 
Table 3 Results of nested case-control analysis, relative risk models

\begin{tabular}{|c|c|c|c|}
\hline & Model $\chi^{2}, 1 \mathrm{df}$ & $\mathrm{RR}^{*}$ & $(95 \% \mathrm{Cl})$ \\
\hline \multicolumn{4}{|l|}{ Continuous exposure measures } \\
\hline Cumulative exposure $\left(\mathrm{mg} / \mathrm{m}^{3}-\mathrm{y}\right)$ & 30.9 & 1.04 & $(1.03$ to 1.06$)$ \\
\hline Average exposure rate over working period $\left(\mathrm{mg} / \mathrm{m}^{3}\right)$ & 19.9 & 2.77 & $(1.80$ to 4.26$)$ \\
\hline Duration of exposure (y) & 27.2 & 1.04 & $(1.02$ to 1.06$)$ \\
\hline Log transformed cumulative exposure (log $\mathrm{mg} / \mathrm{m}^{3}$-days) & 73.2 & 2.08 & $(1.71$ to 2.53$)$ \\
\hline \multicolumn{4}{|l|}{ Log transformed cumulative exposure (log $\mathrm{mg} / \mathrm{m}^{3}$-days) } \\
\hline \multicolumn{4}{|l|}{ By study } \\
\hline 1. US diatomaceous earth workers & & 2.08 & $(1.23$ to 3.52$)$ \\
\hline 2. Finnish granite workers & & 2.76 & $(1.37$ to 5.57$)$ \\
\hline 3. US granite workers & & 1.76 & $(1.30$ to 2.38$)$ \\
\hline 4. US industrial sand workers & & 1.63 & (1.03 to 2.57$)$ \\
\hline 5. US gold miners & & 3.57 & $(1.90$ to 6.69$)$ \\
\hline 6. Australian gold miners & & 2.31 & (1.34 to 3.97$)$ \\
\hline \multicolumn{4}{|l|}{ By age of death (of the cases) } \\
\hline$<65$ years & & 2.70 & (1.90 to 3.84$)$ \\
\hline$\geqslant 65$ years & & 1.81 & (1.44 to 2.29 ) \\
\hline
\end{tabular}

\section{Nested case-control analysis}

Conditional logistic regression showed significantly increased risks of silicosis mortality for all three continuous measures of exposure (cumulative exposure, average exposure, and duration of exposure; see table 3 ).

Both exposure duration and exposure rate (average exposure over working period) played independent roles in the relation between silica exposure and silicosis mortality, which was indicated by the better fit of the model (model $\chi^{2}$ 52.0, 2 df) that included both terms compared with models including the single terms. Table 3 shows that the exposure variable with the best model fit was, however, the log transformed cumulative exposure in $\log \mathrm{mg} / \mathrm{m}^{3}$-days (rate ratio for increase in $1 \log \mathrm{mg} / \mathrm{m}^{3}$-days, $2.08,95 \% \mathrm{CI} 1.71$ to 2.53).

The rate ratio (per $1 \log \mathrm{mg} / \mathrm{m}^{3}$-days) for each cohort for log transformed cumulative exposure ranged between 1.63 and 3.57, all being statistically significant at the 0.05 level. No significant heterogeneity was observed between studies, indicated by little difference in the fit of the models with and without interaction terms for study (change in -2 log likelihoods, 6.6, with $5 \mathrm{df}, \mathrm{p}=0.25$ ). Although the studies showed similar patterns of exposure-response, we examined whether the observed differences between them might have been explained by the differing amounts of time since last exposure in each study. In this respect, studies with more follow up time might be expected to have proportionately more silicosis deaths, and perhaps a steeper exposure-response curve. However, time since last exposure was not an important predictor of silicosis in the model, nor did it have much influence on the heterogeneity of exposure-response between studies.

When the analysis was stratified by age of death of the cases, the exposure-response curve was somewhat steeper for ages less than 65 (table 3). An interaction term testing the difference between the age specific slopes yielded a $\mathrm{p}$ value of 0.07 .

Inclusion of a lag period $(5,10,15$, or 20 years $)$ did not improve the fit over the model with the log of unlagged cumulative exposure.

The cubic spline model showed no improvement over the model using log of cumulative exposure (change in $-2 \log$ likelihood, 1.7, $4 \mathrm{df}, \mathrm{p}=0.63$ ). Results (in terms of the deviance) were similar to the usual exponential relative risk model using the log of cumulative exposure.

\section{Risk assessment}

Cumulative risk of death from silicosis with an exposure of $0.10 \mathrm{mg} / \mathrm{m}^{3}$ from age 20 to $65\left(4.5 \mathrm{mg} / \mathrm{m}^{3}\right.$-years $)$ was estimated to be 13 per 1000 . At an exposure of $0.05 \mathrm{mg} / \mathrm{m}^{3}\left(2.25 \mathrm{mg} / \mathrm{m}^{3}\right.$ years) the cumulative risk of death was estimated to be 6 per 1000.

\section{DISCUSSION}

The pooling of silica exposed cohorts with retrospective exposure data offered for the first time the opportunity to study in detail the quantitative relation between exposure to crystalline silica and silicosis mortality.

Workers included in this study were exposed to crystalline silica in different occupational circumstances. To make the exposure estimate comparable between cohorts, respirable crystalline silica was used as the common unit of exposure. Differences in biological activity of different types of silica dust caused by their physical characteristics (for example, freshly cleaved silica, silica coated with clay) could not be taken into account in this pooled analysis. However, the exposureresponse relation for log transformed cumulative exposure to crystalline silica (the metric that provided the best fit) was comparable between studies and no significant heterogeneity was found. We therefore think that our findings are relevant for different circumstances of occupational exposure to crystalline silica.

For all six cohorts, silicosis deaths were defined for the pooled analysis as those with underlying cause of death silicosis (ICD9 502) or unspecified or unknown pneumoconiosis (ICD9 505). This definition of outcome is specific but not sensitive, since deaths from silicosis might have been attributed to other causes such as tuberculosis or chronic obstructive pulmonary disease with no mention of silicosis or pneumoconiosis. Especially when only a singular underlying cause of death is available, an underestimation of the number of deaths caused by silicosis is likely to occur. ${ }^{41}$

For the overall risk presented here (the estimation of 13 silicosis deaths per 1000 with lifetime exposure under the current standard), the under-report of silicosis deaths will have resulted in an under- rather than overestimation, irrespective of possible differences in exposure levels for unreported cases versus reported cases. The effect of underreporting on the exposure-response curve is more difficult to predict, and would depend on the relative exposure levels of the unreported versus reported cases.

Misclassification of exposure status has inevitably occurred in this pooled analysis, but is not likely to be related to the disease status. A categorical analysis based on broad exposure groups should not be much affected by the resulting level of misclassification. 


\section{Main messages}

- The pooling of six silica exposed cohorts enabled for the first time a detailed study of the quantitative relation between exposure to crystalline silica and silicosis mortality.

- The six cohorts showed similar patterns of exposureresponse for the logarithm of cumulative exposure, without significant heterogeneity between studies.

- Cumulative risk of death from silicosis with an exposure of $0.1 \mathrm{mg} / \mathrm{m}^{3}$ from age 20 to 65 was estimated to be 13 per 1000 .

\section{Policy implications}

- Results indicate that the current exposure standard for crystalline silica used by many countries $\left(0.1 \mathrm{mg} / \mathrm{m}^{3}\right)$, is not sufficiently protective against silicosis mortality.

The log of cumulative exposure provided the best fit to our data in regression analyses. Duration of exposure did not fit nearly as well as the log of cumulative exposure, suggesting that our estimation of exposure level was able to significantly add to simple duration in predicting silicosis, in turn lending some validity to our job-exposure matrices. ${ }^{36}$ The superior fit of the log of cumulative exposure compared with simple cumulative exposure suggests a flattening out of risk at high levels of exposure, a phenomenon which has been seen in occupational mortality studies for other agents, for example, studies of cancer mortality in relation to dioxin, ${ }^{42}$ or diesel fumes. ${ }^{43}$

Including a lag for cumulative exposure did not improve the fit of the models or the risk estimates. While lagging is less important when the follow up time since cessation of exposure is long, in our study there was a wide heterogeneity of time since last exposure. Therefore the lack of improvement using a lag suggests that the whole exposure period was important, including recent periods. A similar finding has been made for silicosis morbidity by Chen and colleagues. ${ }^{8}$

In this pooled analysis it was not possible to adjust for potential confounders, especially cigarette smoking. Some studies suggest that smoking increases the risk of silicosis in exposed workers, ${ }^{44-46}$ although no effect of smoking was detected in a study of Colorado miners. ${ }^{7}$

Silicosis mortality rate was found to be 28 per 100000 person-years for the pooled cohort, and 230 per 100000 for the highest exposure category.

The estimated cumulative risk of silicosis death, assuming exposure at the current OSHA exposure standard $\left(0.1 \mathrm{mg} / \mathrm{m}^{3}\right.$ when dust is $100 \%$ silica) from age 20 to 65 was 13 per 1000 $(1.3 \%)$. For silicosis morbidity (radiographic small opacity profusion of category $1 / 1$ or greater) the cumulative risk at this level of exposure was found to be $40-70 \% .^{6-8}{ }^{47}$ The current standard therefore is not fully protective with respect to being able to entirely prevent the occurrence of either silicosis or death from silicosis.

At an exposure of $0.05 \mathrm{mg} / \mathrm{m}^{3}$ the lifetime silicosis mortality risk was estimated to be 6 per 1000, still above the acceptable threshold of risk of 1 per 1000 used by some agencies, such as the US Occupational Safety and Health Administration. ${ }^{48}$

In conclusion, the findings from our pooled analysis add further support for the need to control silica exposure and to lower the occupational standards.

\section{Authors' affiliations}

A 't Mannetie, P Boffetta, International Agency for Research on Cancer (IARC), Unit of Environmental Cancer Epidemiology, Lyon, France
K Steenland, National Institute for Occupational Safety and Health (NIOSH), Department of Health and Human Services, Robert A Taft Laboratories, Cincinnati, Ohio, USA

M Attfield, National Institute for Occupational Safety and Health (NIOSH), Division of Respiratory Disease Studies, Morgantown, USA H Checkoway, University of Washington, Department of Epidemiology, Seattle, USA

N DeKlerk, University of Western Australia, Department of Public Health Perth, Australia

R-S Koskela, Finnish Institute of Occupational Health (FIOH), Department of Epidemiology and Biostatistics, Helsinki, Finland

\section{REFERENCES}

1 Kauppinen T, Toikkanen J, Pedersen D, et al. Occupational exposure to carcinogens in the European Union. Occup Environ Med 2000;57:10-18

2 NIOSH. Work-related diseases surveillance report 91-113. Cincinnati, $\mathrm{OH}$ : National Institute for Occupational Safety and Health, 1991.

3 Kogevinas M, Boffetta P, Pearce N. Occupational exposure to carcinogens in developing countries. Occupational Cancer in Developing Countries. Lyon, 1994

4 Greaves IA. Not-so-simple silicosis: a case for public health action. Am J Ind Med 2000;37:245-5 1

5 Hnizdo E, Sluis-Cremer GK. Risk of silicosis in a cohort of white South African gold miners. Am J Ind Med 1993:24:447-57.

6 Steenland K, Brown D. Silicosis among gold miners: exposure-response analyses and risk assessment. Am J Public Health 1995;85:1372-7.

7 Kreiss K, Zhen B. Risk of silicosis in a Colorado mining community. Am J Ind Med 1996;30:529-39.

8 Chen W, Zhuang Z, Attfield MD, et al. Exposure to silica and silicosis among tin miners in China: exposure-response analyses and risk assessment. Occup Environ Med 2001;58:31-7.

9 Park R, Rice F, Stayner L, et al. Exposure to crystalline silica, silicosis, and lung disease other than cancer in diatomaceous earth industry workers: a quantitative risk assessment. Occup Environ Med 2002:59:36-43.

10 Checkoway H, Heyer NJ, Seixas NS, et al. Dose-response associations of silica with nonmalignant respiratory disease and lung cancer mortality in the diatomaceous earth industry. Am J Epidemiol 1997;145:680-8.

11 Steenland K, Mannetje A, Boffetta P, et al. Pooled exposure-response analyses and risk assessment for lung cancer in 10 cohorts of silica-exposed workers: an IARC multicentre study. Cancer Causes Control 2001; 12:773-84.

12 Seixas NS, Heyer NJ, Welp EA, et al. Quantification of historical dust exposures in the diatomaceous earth industry. Ann Occup Hyg 1997:41:591-604.

13 Koskela R-S, Klockars M, Jarvinen E, et al. Mortality and disability among granite workers. Scand J Work Environ Health 1987;13:18-25.

14 Koskela R-S, Klockars M, Jarvinen E, et al. Cancer mortality of granite workers. Scand J Work Environ Health 1987:13:26-31.

15 Koskela R-S, Klockars M, Laurent $\mathrm{H}$, et al. Silica dust exposure and lung cancer. Scand J Work Environ Health 1994;20:407-16.

16 Koskela R-S. Association of silica dust exposure with lung cancer and other diseases. Acta Universitatis Tamperensis, ser A vol. 460. University of Tampere, Finland, 1995.

17 Davis LK, Wegman DH, Monson RR, et al. Mortality experience of Vermont granite workers. Am J Ind Med 1983;4:705-23.

18 Costello J, Graham WG. Vermont granite workers' mortality study. Am J Ind Med 1988;13:483-97.

19 Attfield M, Costello J. Quantitative exposure-response for silica dust and lung cancer in Vermont granite workers. Submitted for publication.

20 Russell AE, Britten RH, Thompson LR, et al. The health of workers in the dustry trades. II. Exposure to siliceous dust (granite industry). US Public Health Service. 187. Washington, DC, 1929.

21 Bloomfield J, Waldemar C. Silicosis among granite workers. Public Health Rep 1934;49:679-84.

22 Urban DJ. Ventilation in the granite industry. J Ind Toxicol 1939;21:57-67.

23 Hosey AD, Ashe HB, Trasko VM. Control of silicosis in the Vermont granite industry. PHS Publication No. 557. Washington, DC: USHEW 1957.

24 Theriault GP, Burgess WA, DiBerardinis $L$, et al. Dust exposure in the Vermont granite sheds. Arch Environ Health 1974;28:12-17.

25 Eisen EA, Smith TJ, Wegman DH, et al. Estimation of long term dust exposures in the Vermont granite sheds. Am Ind Hyg Assoc J 1984:45:89-94

25 a Streenland K, Sanderson W. Lung cancer among industrial sand workers exposed to crystalline silica. Am J Epidemiol 2001; 153:695-703

26 Sanderson WT, Steenland K, Deddens JA. Historical respirable quartz exposures of industrial sand workers: 1946-1996. Am J Ind Med 2000;38:389-98.

27 Steenland K, Brown D. Mortality study of gold miners exposed to silica and nonasbestiform amphibole minerals: an update with 14 more years of follow-up. Am J Ind Med 1995;27:217-29.

28 Brown D, Kaplan S, Zumwalde R, et al. Retrospective cohort mortality study of underground gold mine workers. In: Goldsmith DWDSC, ed. Silica, silicosis, and lung cancer. New York: Praeger, 2002:31 1-66.

29 Zumwalde R, Ludwig H, Dement J. Industrial Hygiene Report-Homestake Mining Company, Lead, South Dakota. Cincinnati, Ohio, Industry-wide studies branch, DSHEFS, NIOSH, 1981 
30 de Klerk NH, Musk AW, Teblow S, et al. Preliminary study of lung cancer mortality among Western Australian gold miners exposed to silica. Scan J Work Environ Health 1995;21:66-8.

31 de Klerk NH, Musk AW. Silica compensated silicosis, and lung cancer in Western Australian goldminers. Occup Environ Med 1998;55:243-8.

32 Hewson GS. Estimates of silica exposure among metalliferous miners in Western Australia (1925-1993). Perth: Department of Minerals and Energy, Western Australia, 1993.

33 Chen J, Mclaughlin JK, Zhang JY, et al. Mortality among dust-exposed Chinese mine and pottery workers. J Occup Med 1992:34:311-16.

34 McLaughlin JK, Chen JQ, Dosemeci M, et al. A nested case-control study of lung cancer among silica exposed workers in China. Br J Ind Med 1992;49:167-71.

35 Hnizdo E, Murray KJ, Klempman S. Lung cancer in relation to exposure to silica dust, silicosis and uranium production in South African gold miners. Thorax 1997;52:271-5.

36 Mannetje A, Steenland K, Checkoway H, et al. Development of quantitative exposure data for a pooled exposure-response analysis of 10 silica cohorts. Am J Ind Med. Accepted for publication.

37 Steenland K, Deddens JA. Increased precision using countermatching in nested case-control studies. Epidemiology 1997;8:238-42.

38 SAS. SAS User's Guide: Statistics (Version 6.07). SAS Institute Cary, NC, 1991.

39 Harrell FE, Lee KL, Pollock BG. Regression models in clinical studies: determining relationships between predictors and response. J Natl Cancer Inst 1988;80: 1198-202.
40 Kleinbaum D, Kupper L, Morgenstern H. Epidemiological research. Belmont, 1982

41 Cottrell A, Schwartz E, Sokas R, et al. Surveillance of sentine occupational mortality in the District of Columbia: 1980 to 1987. Am J Public Health 1992:82:117-19.

42 Steenland K, Piacitelli L, Deddens J, et al. Cancer, heart disease, and diabetes in workers exposed to 2,3,7,8-tetrachlorodibenzo-p-dioxin. J Natl Cancer Inst 1999;91:779-86.

43 Steenland K, Deddens J, Stayner L. Diesel exhaust and lung cancer in the trucking industry: exposure-response analyses and risk assessment. Am J Ind Med 1998;34:220-8.

44 Finkelstein MM. Silicosis surveillance in Ontario: detection rates, modifying factors, and screening intervals. Am J Ind Med 1994;25:257-66.

45 Rosenman KD, Reilly M, Rice C, et al. Silicosis among foundry workers. Implication for the need to revise the OSHA standard. Am J Epidemiol 1996;144:890-900.

46 Hughes JM, Weill H, Checkoway H, et al. Radiographic evidence of silicosis risk in the diatomaceous earth industry. Am J Respir Crit Care Med 1998;158:807-14.

47 Hnizdo E, Sluis Cremer GK. Silica exposure, silicosis, and lung cancer: a mortality study of South African gold miners. Br J Ind Med $1991 ; 48: 53-60$.

48 Rodricks JV, Brett SM, Wrenn GC. Significant risk decisions in federal regulatory agencies. Regul Toxicol Pharmacol 1987;7:307-20.

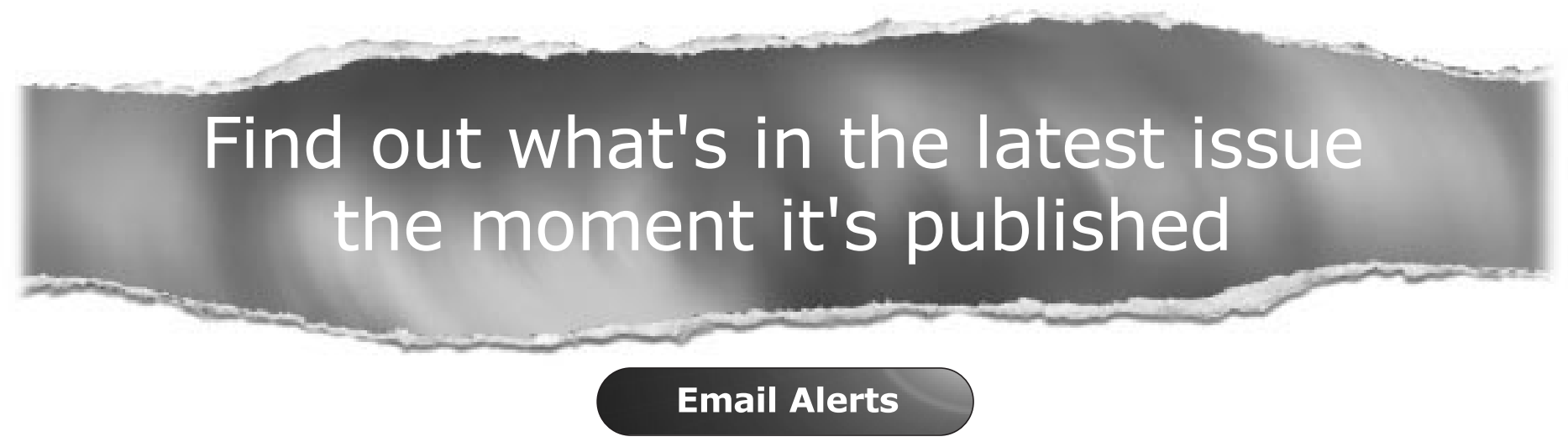

Sign up to receive the table of contents by email every month. You can select from three alerts: Table of Contents (full), TOC Awareness (notice only); Occupational and Environmental Medicine related announcements. 